\title{
European League Against Rheumatism recommendations for the inclusion of patient representatives in scientific projects
}

\author{
M P T de Wit, ${ }^{1}$ S E Berlo, ${ }^{2}$ G J Aanerud ${ }^{3}$ D Aletaha, ${ }^{4} \mathrm{~J}$ W Bijlsma, ${ }^{5}$ L Croucher, ${ }^{6}$ \\ J A P Da Silva, ${ }^{7}$ B Glüsing, ${ }^{8}$ L Gossec, ${ }^{9}$ S Hewlett, ${ }^{10}$ M Jongkees, ${ }^{11}$ D Magnusson, ${ }^{12}$ \\ M Scholte-Voshaar, ${ }^{13}$ P Richards, ${ }^{14}$ C Ziegler, ${ }^{15}$ T A Abma ${ }^{1}$
}

${ }^{1}$ Department of Medical Humanities, VU Medical Centre, Amsterdam, The Netherlands ${ }^{2}$ Department of Paediatric Immunology, University Medical Centre Utrecht, The Netherlands

${ }^{3}$ National Resource Centre for Rehabilitation in Rheumatology, Diakonhjemmet Hospital, Oslo, Norway

${ }^{4}$ Medical University of Vienna, Vienna, Austria

${ }^{5}$ Department of Rheumatology and Clinical Immunology, University Medical Centre Utrecht, Utrecht, The

Netherlands

${ }^{6}$ Arthritis Research UK,

Chesterfield, UK

${ }^{7}$ Serviço de Reumatologia, Hospitais da Universidade de Coimbra, Coimbra, Portugal ${ }^{8}$ EULAR Secretariat, Zurich, Switzerland

${ }^{9}$ Rheumatology B Department, Paris Descartes University, Cochin Hospital, Paris, France

${ }^{10}$ Department of Health and Life Sciences, University of the West of England, Bristol, UK

${ }^{11}$ EULAR Task Force, Leiden,

The Netherlands

${ }^{12}$ Reumatikerforbundet,

Stockholm, Sweden

${ }^{13}$ Dutch League of Arthritis Patient Associations,

Amersfoort, The Netherlands

${ }^{14}$ OMERACT Patient Panel,

Academic Rheumatology, University of Bristol, Bristol, UK

${ }^{15}$ Danish Network of

Patient Research Partners,

Copenhagen, Denmark

\section{Correspondence to}

M P T de Wit, Department of Medical Humanities, VU

Medical Centre, Van der Boechorststraat 7, 1081 BT

Amsterdam, The Netherlands; martinusdewit@hotmail.com

Accepted 11 November 2010 Published Online First 20 January 2011

\begin{abstract}
Objective To develop recommendations to enable successful inclusion of the patient perspective in European League Against Rheumatism (EULAR)-funded scientific research projects.
\end{abstract}

Methods The EULAR standardised operational procedures for guideline development were followed. A systematic literature review was presented during a first task force meeting, including 3 rheumatologists, 1 rheumatologist/epidemiologist, 2 allied health professionals, 2 representatives of arthritis research organisations and 7 patient representatives, resulting in 38 statements. A Delphi method was carried out to reduce and refine the statements and agree on a set of eight. Next, a survey among a wider group of experts, professionals and patient representatives $(n=42)$, was completed. Feedback from this wider group was discussed at the second meeting and integrated in the final wording of the recommendations. Subsequently, the level of agreement of the group of experts $(n=81)$ was re-evaluated.

Results The project resulted in a definition of patient research partner and agreement on a set of eight recommendations for their involvement in research projects. These recommendations provide practical guidance for organising patient participation, capturing (1) the role of patient research partners, (2) phase of involvement, (3) the recommended number, (4) recruitment, (5) selection, (6) support, (7) training and (8) acknowledgement.

Conclusion Collaboration between patients and professionals in research is relatively new. Trials or effectiveness studies are not yet available. Nevertheless, it is possible to define recommendations for the inclusion of patients in research following a solid expert opinion based consensus process.

\section{INTRODUCTION}

Active collaboration between patients and researchers seems to be an appropriate means to capture the patient perspective. Patient participation ensures better representation of their needs and uncertainties, and helps preventing a potential mismatch between their preferences and the scientific focus in research. ${ }^{12}$ Other potential benefits are more patient oriented health research agendas, ${ }^{3}$ gaining trust and access to patient organisations and other institutions, ${ }^{45}$ raising funds for research, ${ }^{6}$ and creating support for implementation. ${ }^{57}$ Patient involvement may result in their empowerment and enhance the sense of ownership. ${ }^{89}$ Finally the development of an involved community that is better informed and recognises the value and limitations of research will be fostered. ${ }^{\text {? }}$

In the field of arthritis research the Cochrane Musculoskeletal Consumer Group, ${ }^{67}$ conferences on Outcome Measures in Rheumatology (OMERACT) 1011 and the Rheumatoid Arthritis Impact of Disease (RAID) project ${ }^{12}$ have successfully used advanced concepts of patient participation. Publications tend to demonstrate that the benefits outweigh the drawbacks ${ }^{513}$ but lessons learnt have not yet been systematically evaluated and published. The European League Against Rheumatism (EULAR) standardised operational procedures do not contain guidelines for the involvement of patients. ${ }^{14}$ It has however become usual practice to include one or more patient representatives in EULAR scientific projects. Although many researchers intend to incorporate the patient perspective in their work, they are faced with numerous difficulties in optimising the participation of patients. For this reason EULAR initiated a task force to develop recommendations for the inclusion of patient research partners in EULARfunded scientific projects.

The task force discussed the ideal patient representative and developed a definition: patient research partners are "persons with a relevant disease who operate as active research team members on an equal basis with professional researchers, adding the benefit of their experiential knowledge to any phase of the project'. It is expected that these recommendations will be useful to researchers and patient research partners within and without the EULAR community. Throughout this report the term 'partner' will be used to refer to patient research partner.

\section{METHODS}

A task force was formed and met twice, bringing together three rheumatologists, one rheumatologist/epidemiologist, two allied health professionals, two representatives of research organisations and eight patient research partners, coming from six European countries, with extensive expertise and experience in the field of patient-centred research. In line with the EULAR standardised operational procedures, ${ }^{14}$ the first two authors performed a systematic literature review (SLR). A Delphi method was used to agree on eight recommendations. 
A wider expert group, professionals and patient representatives, nominated by all task force members, evaluated the recommendations in two rounds using web-based software. ${ }^{15}$ Feedback from the first round $(n=42)$ was discussed at the second meeting and integrated in the final wording of the recommendations. Subsequently, the level of agreement was evaluated again by a group of experts consisting of 28 patient representatives and 53 professionals.

\section{RESULTS}

The results of a SLR were discussed during the first task force meeting. Four databases were searched for references on active patient participation in rheumatology research, which resulted in a few articles. It became clear that it is difficult to define unequivocal terms for the level of patient involvement in research under discussion in this project. We found several references to lower levels of patient participation, most of them related to inclusion of patients in clinical trials or patients as respondents in prioritisation or agenda-setting projects. A second search resulted in almost 50 references, mainly outside rheumatology. After controlling full texts 22 articles were considered relevant and included.

The first 2 authors then formulated 38 statements. These statements were reduced to eight recommendations using the Delphi method involving all task force members. During three rounds items were excluded, combined and reworded. Statements with more than $50 \%$ approval were included.

The eight recommendations were appraised by a wider group of experts. Feedback from this wider group was discussed at the second task force meeting and integrated in the final wording of the recommendations (table 1). Subsequently, these recommendations were again evaluated by a group of experts $(n=81)$. Figure 1 shows the results of this evaluation. For each recommendation additional clarification and potential benefits will be provided.

\section{Role}

Statement: participation of patient research partners is strongly recommended for clinical research projects and for the development of recommendations and guidelines, and should be considered for all other research projects.

Authorities such as the US Food and Drug Administration (FDA) and European Medicines Agency (EMEA) promote the inclusion of patient reported outcomes in clinical trials. ${ }^{16} 17$ This is consistent with a broader tendency to include the patient perspective in clinical outcome research. ${ }^{2}$ Experiential knowledge is knowledge based on introspection and the shared reflection of illness experiences, and considered a valid source of knowledge. ${ }^{41819}$ It covers all domains of life; rather than knowledge about the illness it involves knowledge how to integrate the illness in daily life. ${ }^{19}$

Even for laboratory-based research evidence exists that patient participation benefits the research process as well as the outcomes. $^{20}$ Their involvement might focus on agenda setting, ${ }^{921}$ prioritisation, optimising conditions for sound research (sufficient funding, supportive legislation and ethical issues) and dissemination. The present group suggests that if partners are not included, this should be justified.

\section{Phases of research}

Statement: participation of patient research partners should be considered in all phases of the project to provide experiential knowledge, with the aim of improving the relevance, quality and validity of the research process.

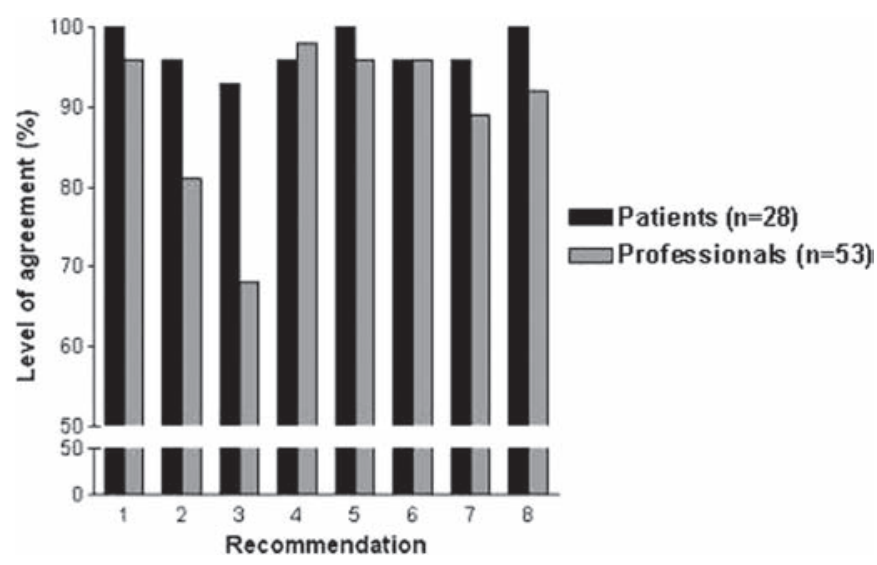

Figure 1 Level of agreement with the recommendations measured by a five-item Likert scale (1, fully agree; 2 , agree; 3 , indifferent; 4 , disagree; 5, fully disagree). The level of agreement is expressed as the sum of answers 1 and 2 divided by the number of respondents multiplied by $100 \%$.

Table 1 Recommendations for the inclusion of patient representatives in scientific projects and the level of agreement among task force members and the group of experts $(n=81)$

\begin{tabular}{|c|c|c|c|}
\hline & & \multicolumn{2}{|c|}{$\underline{\text { Respondents agreeing (\%) }}$} \\
\hline \multicolumn{2}{|c|}{ Recommendations } & $\begin{array}{l}\text { Patients } \\
(\mathrm{n}=\mathbf{2 8})\end{array}$ & $\begin{array}{l}\text { Professionals } \\
(n=53)\end{array}$ \\
\hline 1 & $\begin{array}{l}\text { Participation of patient research partners is strongly recommended for clinical research projects and } \\
\text { for the development of recommendations and guidelines, and should be considered for all other } \\
\text { research projects. }\end{array}$ & 100 & 96 \\
\hline 2 & $\begin{array}{l}\text { Participation of patient research partners should be considered in all phases of the project to provide } \\
\text { experiential knowledge, with the aim of improving the relevance, quality and validity of the research } \\
\text { process. }\end{array}$ & 96 & 81 \\
\hline 5 & $\begin{array}{l}\text { The selection process of patient research partners should take into account communication skills, } \\
\text { motivation and constructive assertiveness in a team setting. }\end{array}$ & 100 & 96 \\
\hline 6 & $\begin{array}{l}\text { The principal investigator must facilitate and encourage the contribution of patient research partners, } \\
\text { and consider their specific needs. }\end{array}$ & 96 & 96 \\
\hline 7 & $\begin{array}{l}\text { The principal investigator must ensure that patient research partners receive information and training } \\
\text { appropriate to their roles. }\end{array}$ & 96 & 89 \\
\hline
\end{tabular}


Patient research partners must be an integral part of the project with the same rights and opportunities to participate in the entire process as other participants. ${ }^{7}$ It is essential that they are included from the very beginning when decisive choices are made. ${ }^{4}$ Their involvement in the protocol design stage may impact research objectives, questions and methods, and raise the level of attention for the dissemination of outcomes. ${ }^{22}$ Using experiential knowledge during all phases of the project can contribute to the relevance, quality and validity of the research outcomes. ${ }^{4}$ Continued patient involvement is a prerequisite for patient-oriented outcomes. ${ }^{9}{ }^{21}$ Partners can perform several tasks, depending on their expertise and the type of project. The principal investigator should discuss their expected contributions and any support required at the start of the project and continue to encourage the dialogue as the project progresses. ${ }^{89}$ Deviation from this recommendation should always be explained in the publication.

\section{Recommended number}

Statement: a minimum of two patient research partners should be involved in each project.

The principal investigator should consider an appropriate number of partners on the team before the start of the project. The number depends on the topic and project objective. There is no solid evidence for the need to recruit a minimum of two partners in the literature, but several benefits are consistently reported and found to have face validity by the task force members. There is always the risk of absence due to the unpredictable nature of a rheumatic condition that can be overcome if an adequate substitute is available on the team. Furthermore, a lower number might compromise the patient perspectives because of dominancy of the professionals' voice. ${ }^{4} 2022-24$ Other benefits include increased (self)-confidence of the partner, the opportunity to discuss issues with other partners and improving the level of preparation. ${ }^{4} 8222425$ Because patients' experiences are naturally diverse, a minimum of two partners will provide diversity of preferences and opinions. ${ }^{9} 2126$

\section{Recruitment}

Statement: identification of potential patient research partners should be supported by a clear description of expected contributions.

Although many criteria for selecting partners are mentioned in the literature, no critical appraisal of their value is available. Consensus exists on the usefulness of a task description to make mutual expectations more explicit and to avoid disappointments. ${ }^{22}$ This description should clarify the respective roles of the partner in contributing to the research process and of the principal investigator in providing adequate support.

The task description will also contain minimum requirements, depending on the aim of the project and the expected contribution of the partners. Personal experience of living with a relevant rheumatic disease is mandatory. However, in some cases, for instance children with juvenile idiopathic arthritis, it might be appropriate to include family members (proxies). ${ }^{9} 21$

We found few references to the procedure of recruiting partners. ${ }^{10} 12 \quad 2227 \quad 28$ Currently different procedures are applied, depending on the aim of patient participation in the project. When individual personal experience of a particular disease or treatment is required, the principal investigator might recruit partners through the clinics of project members. ${ }^{22}$ This procedure effectively uses the personal impact of long-term conditions and was followed for the development of the RAID. ${ }^{12}$ When seeking the opinions and support of a larger patient group the principal investigator might invite experienced patient advocates to join the project group via established patient networks (EULAR standing committee of People with Arthritis/Rheumatism in Europe, national patient organisations). Sometimes a mixed method of recruitment is applied, for example, for OMERACT. ${ }^{10}$

\section{Selection}

Statement: the selection process of patient research partners should take into account communication skills, motivation and constructive assertiveness in a team setting.

The primary selection factors relate to attitude and communication skills. Ideally partners have a critical though constructive and proactive attitude. 'Critical' means to be able to 'interrupt a professor in full flow', 22 or to question the validity of statements irrespective of their author. Sometimes it might become difficult to complement or disagree with professionals with whom the partner has a clinical relationship. ${ }^{22}$ In that case it is helpful to make mutual expectations more explicit. The partner and the researcher should be able to compartmentalise different roles: the role of a patient and a doctor in the clinic, and the role of a partner or colleague in the project team. ${ }^{22}$

A 'constructive' attitude is mandatory for successful collaboration. Good communication skills are needed to express personal experiences to professionals in a compelling and useful manner. The capacity to read, write and speak English is essential for reviewing literature and to participate in international project meetings. For national projects this may not be obligatory.

Partners do not require academic training and do not need to become 'professional researchers'. A medical background can even be a contraindication because professional knowledge may tend to become dominant. ${ }^{4}$ Thinking like an outsider is crucial to provide experiential knowledge. A basic familiarity with medical terminology however is useful. This should be verified before the start of the project and background information or training should be provided if necessary.

Task description and requirements need to be carefully introduced by a personal approach. Some partners might be scared off or feel unable to contribute if the information is very formal.

\section{Support}

Statement: the principal investigator must facilitate and encourage the contribution of patient research partners, and consider their specific needs.

The support and attitude of the principal investigator are crucial to allow full patient contribution. ${ }^{22}$ Good communication is the key to success. ${ }^{29}$ It is useful to ask specifically for partners' needs before the start of the project: Do they understand the purpose and time frame of the project? Is the research protocol clear? Do they have access to relevant information? Are summaries or glossaries ${ }^{30}$ in lay language available? Do they have special requirements regarding personal assistance, timing of meetings, transport or access to accommodation? Discuss expectations, tasks and cooperation at an early stage to give partners time to familiarise themselves with the information. Facilitating training opportunities or travel bursaries might be considered.

The principal investigator should create a safe and respectful environment during the meetings emphasising their equality and encouraging partners to tell their personal story. 4822 The result should be interaction, mutual learning and ultimately the integration of scientific knowledge and patients' experiences. ${ }^{9} 31$

Specific attention should be given to the issue of overburdening. ${ }^{22}$ Sometimes financial compensation will 
allow partners to participate. Reimbursement of all costs, even sometimes in advance, is obligatory.

Appropriate skills to make use of patient expertise may not come naturally. Principal investigators and other team members should master them or receive appropriate training.

\section{Training}

Statement: the principal investigator must ensure that patient research partners receive information and training appropriate to their roles.

Training opportunities for partners are desirable. ${ }^{6} 722$ Partners often fear moving into a new field of activities and they might feel reluctant to express themselves. They might think that their contribution is irrelevant to research ${ }^{22}$ and doubt their input will be heard. ${ }^{26}$ Appropriate training increases expertise and understanding of research methods and will promote their self-confidence. Training will also help them share their personal experience with other patients and become more capable to go above their individual narrative. They may develop a more integrated view on their condition, which will empower them to represent a broader patient perspective. Finally, training should make them aware of ethical issues such as confidentiality, privacy and legislation.

Although formal and specific training may save valuable time, training on the job remains important for developing necessary skills.

\section{Acknowledgement}

Statement: the contribution of patient research partners to projects should be appropriately recognised, including coauthorship when eligible.

Participation of partners is usually voluntary work and an appropriate token of appreciation should be considered. There are various ways to express gratitude for their efforts. In some countries partners may receive an honorary contract, ${ }^{22}$ access to (electronic) scientific libraries, a travel bursary or subscription to a national rheumatology journal. Training opportunities are also seen as a valuable incentive.

Research institutions might develop a certificate for partners acknowledging their contribution in a project. When results are published, it is important for reasons of transparency to make the reader aware of the partners' collaboration and to avoid their participation being seen as tokenism. ${ }^{32}$ When partners fulfil the International Committee of Medical Journal Editors criteria for coauthorship, ${ }^{33}$ they should become coauthors. ${ }^{22}$ In other cases their involvement might be acknowledged separately.

Payment is an important aspect for partners feeling valued for their contribution, while others may wish to donate their time for free. ${ }^{34}$ In some countries access to state disability benefits may be threatened if payment is offered. ${ }^{35}$ No consensus could be reached in our task force meetings and supportive literature is weak. Further research is necessary before an appropriate recommendation on payment can be made.

\section{DISCUSSION}

Patient participation in research is desirable and irreversible. A growing number of publications highlights the theoretical benefits. ${ }^{36}$ Implementation of the presented recommendations may enhance patient involvement in rheumatology as partners. Nevertheless obstacles remain that complicate the collaboration between professionals and patients. They are partly reflected in figure 1. Although patients and professionals support the inclusion of partners in research, their opinions about the phases of involvement (recommendation 2) and the recommended number (recommendation 3 ) differ. A reason for the relatively low level of agreement by professionals for recommendation 2 might be the opinion that partners add value at the start of a project (defining research questions and relevant outcomes) and at the end (dissemination and implementation) but may have a limited ability to contribute to developing research design, collecting data and analysis; the difference in agreement with recommendation 3 might be explained by the perception of professionals that there is a limited role for patient involvement in laboratory research, while some patients feel more comfortable when they can act among their peers: 'It feels like a huge responsibility being the only one to represent the patient voice, when you can only talk from your own experience' (Anonymous patient, survey 2009).

Other causes for potential obstacles are asymmetrical relationships between patients and professionals. ${ }^{4} 202223$ The professional perspective is dominant and patients look up to scientific experts. Therefore, patients' experiential knowledge and input are easily overruled, perhaps unintentionally. ${ }^{11}$ Professional hierarchy (eg, titles) can be a factor for reluctance or nervousness to speak up during these meetings. ${ }^{29}$ It is reported that patients for this reason may adopt the opinion of professionals or change their own views. ${ }^{4}{ }^{24}$ Creating supportive conditions and providing education for all stakeholders may establish more equal and sustainable partnerships.

An unresolved issue is the 'representativeness' of patient research partners. ${ }^{25}$ 'The' patient does not exist. One should be aware that selecting partners according to recommendations 4 and 5 might cause bias. It might exclude views of people who are not able to speak English, who have no opportunity to travel because of their disease or who have cognitive or social limitations. Alternative ways of recruiting partners should be studied.

The issue of representativeness is a responsibility of the entire project team. Team members may expect partners to go beyond their individual experience and to represent the views of other patients living with similar conditions. However, unless advice is specifically sought from a patient organisation, a patient research partner does not participate as a patient advocate, but in a personal capacity with the purpose of contributing their own views, based on their own experience of the impact of their condition on their lives. More research is recommended to explore various methods for patient group consultation.

There is debate whether partners who contribute over longer periods of time start to become 'professional' patients. Professionals might argue that these partners risk losing touch with their fellow patients and alienate themselves from the target group, ${ }^{4}$ or they might represent the views of special interest groups. ${ }^{31}$ At our task force meetings, the experienced patient research partners voiced strongly that whatever their cumulative experiences, they 'still wake up every day with arthritis', an experience that does not change, and which the professionals do not have.

Last obstacle is the lack of robust evidence about the added value of patient participation in research. We hope that our recommendations will help to overcome the above-mentioned obstacles. The results of our survey strengthen our confidence that these recommendations will contribute to equal involvement of patients in research, within the field of rheumatology as well as beyond. Implementation of these recommendations should be evaluated to document the effectiveness of patient participation in practice. Principal investigators should be encouraged to report on the benefits and barriers of these recommendations. 
Funding This study was supported by a research grant from EULAR (PAR009).

Competing interests None.

Provenance and peer review Not commissioned; externally peer reviewed.

\section{REFERENCES}

1. Tallon D, Chard J, Dieppe P. Relation between agendas of the research community and the research consumer. Lancet 2000;355:2037-40.

2. Nicklin J, Cramp F, Kirwan J, et al. Collaboration with patients in the design of patient reported outcome measures: capturing the experience of fatigue in rheumatoid arthritis. Arthritis Care Res (Hoboken) 2010;62:1552-8.

3. Oliver S, Gray J, et al. A Bibliography of Research Reports about Patients', Clinicians and Researchers' Priorities for New Research. London: James Lind Alliance, 2006.

4. Abma TA, Molewijk B, Widdershoven GA. Good care in ongoing dialogue. Improving the quality of care through moral deliberation and responsive evaluation. Health Care Anal 2009;17:217-35.

5. Kjeken I, Ziegler C, Skrolsvik J, et al. How to develop patient-centered research: some perspectives based on surveys among people with rheumatic diseases in Scandinavia. Phys Ther 2010;90:450-60.

6. O'Connell D, Mosconi P. An active role for patients in clinical research. Drug Dev Res 2006;67:188-92

7. Shea B, Santesso N, Qualman A, et al. Consumer-driven health care: building partnerships in research. Health Expect 2005;8:352-9.

8. Schipper K, Abma T, van Zadelhoff E, et al. What does it mean to be a patient research partner? An ethnodrama. Qual Inq 2010;16:10.

9. Abma TA, Nierse CJ, Widdershoven GA. Patients as partners in responsive research: methodological notions for collaborations in mixed research teams. Qual Health Res 2009;19:401-15.

10. Kirwan J, Heiberg T, Hewlett S, et al. Outcomes from the Patient Perspective Workshop at OMERACT 6. J Rheumatol 2003;30:868-72.

11. Kirwan JR, Ahlmén M, de Wit M, et al. Progress since OMERACT 6 on including patient perspective in rheumatoid arthritis outcome assessment. J Rheumatol 2005;32:2246-9.

12. Gossec L, Dougados M, Rincheval N, et al. Elaboration of the preliminary Rheumatoid Arthritis Impact of Disease (RAID) score: a EULAR initiative. Ann Rheum Dis 2009;68:1680-5.

13. Thornton H. Patients and health professionals working together to improve clinical research: where are we going? Eur J Cancer 2006;42:2454-8.

14. Dougados M, Betteridge N, Burmester GR, et al. EULAR standardised operating procedures for the elaboration, evaluation, dissemination, and implementation of recommendations endorsed by the EULAR standing committees. Ann Rheum Dis 2004;63:1172-6.

15. SurveyMonkey. SurveyMonkey software. http://www.surveymonkey.com (accessed 2009)

16. Speight J, Barendse SM. FDA guidance on patient reported outcomes. BMJ 2010;340:c2921.

17. Rowen D, Carlton J, Brazier JE, et al. FDA on PROMs. Two important points. BMJ 2010;341:c5454.
18. Caron-Flinterman JF, Broerse JE, Bunders JF. The experiential knowledge of patients: a new resource for biomedical research? Soc Sci Med 2005:60:2575-84.

19. Haaster H, Koster-Dreese Y,.eds. Ervaren en weten - essays over de relatie tussen ervaringskennis en onderzoek. Utrecht: Jan van Arkel, 2005.

20. Caron-Flinterman JF, et al. New Voice in Science: Patient Participation in DecisionMaking on Biomedical Research (Dissertation). Amsterdam: Free University of Amsterdam, 2005.

21. Abma TA, Broerse JE. Patient participation as dialogue: setting research agendas. Health Expect 2010;13:160-73.

22. Hewlett S, Wit M, Richards P, et al. Patients and professionals as research partners: challenges, practicalities, and benefits. Arthritis Rheum 2006:55:676-80.

23. Abma TA. Patient participation in health research: research with and for people with spinal cord injuries. Qual Health Res 2005;15:1310-28.

24. Broerse J, van der Ham L, van Veen S, et al. Inventarisatie patientenparticipatie bij richtlijnontwikkeling [Internal desk study: Inventory patient participation in guideline development. In Dutch]. Amsterdam, The Netherlands: Athena Institute, VU Amsterdam, 2010.

25. van Wersch A, Eccles M. Involvement of consumers in the development of evidence based clinical guidelines: practical experiences from the North of England evidence based guideline development programme. Oual Health Care 2001;10:10-16.

26. Schipper K, Abma TA, Hené RJ, et al. Polycystic kidney disease. BMJ 2009;338:b1595.

27. Kiltz U, van der Heijde D, Mielants $H$, et al. ASAS/EULAR recommendations for the management of ankylosing spondylitis: the patient version. Ann Rheum Dis 2009;68:1381-6.

28. van der Goes MC, Jacobs JW, Boers M, et al. Patients' and rheumatologists perspectives on glucocorticoids: an exercise to improve the implementation of the European League Against Rheumatism (EULAR) recommendations on the management of systemic glucocorticoid therapy in rheumatic diseases. Ann Rheum Dis 2010;69:1015-21.

29. Lanza ML, Ericsson A. Consumer contributions in developing clinical practice guidelines. J Nurs Care Qual 2000;14:33-40.

30. Richards P, de Wit M. OMERACT Glossary. http://reuma.rediris.es/omeract/docs/ OMERACT-Glossary.htm (accessed 24 March 2010).

31. Liberati A. Consumer participation in research and health care. BMJ 1997;315:499.

32. Facey K, Boivin A, Gracia J, et al. Patients' perspectives in health technology assessment: a route to robust evidence and fair deliberation. Int J Technol Assess Health Care 2010;26:334-40.

33. International Committee of Medical Journal Editors. Uniform Requirements for Manuscripts. http://www.icmje.org (accessed 24 March 2009).

34. Bastian H. Raising the standard: practice guidelines and consumer participation. Int J Qual Health Care 1996;8:485-90.

35. Involve. People \& Participation: How to Put Citizens at the Heart of Decision-Making London: Beacon Press, 2005

36. Staley K. Summary Exploring Impact: Public Involvement in NHS, Public Health and Social Care Research. Eastleigh: Involve, 2009. 